\title{
Outcome of successful graft take of Integra and split thickness skin graft after the release of post-burn neck contracture.
}

1. MBBS, FCPS

Assistant Professor Plastic Surgery D.G Khan Medical College, D.G Khan

2. MBBS, FCPS

Senior Registrar Plastic Surgery Jinnah Burn and Reconstructive Surgery Center Lahore.

3. MBBS, FCPS

Assistant Professor Plastic Surgery Jinnah Burn and Reconstructive Surgery Center Lahore.

4. MBBS, FCPS

Associate Professor Plastic Surgery Jinnah Burn and Reconstructive Surgery Center Lahore.

5. MBBS

Medical Officer Plastic Surgery Jinnah Burn and Reconstructive Surgery Center Lahore.

6. MBBS, FRCS, FCPS

Professor of Plastic Surgery Jinnah Burn and Reconstructive Surgery Center Lahore.

Correspondence Address: Dr. Abdul Malik Mujahid Department of Plastic Surgery Ghazi Medical College DG Khan. iqbalian_127@yahoo.com

Article received on: 24/03/2020

Accepted for publication: 20/05/2020
Abdul Malik Mujahid', Faraz Ahmed Tarar ${ }^{2}$, Farrukh Aslam Khalid ${ }^{3}$, Yawar Sajjad ${ }^{4}$, Usman Ishaque ${ }^{5}$, Moazzam Nazeer Tarar $^{6}$

ABSTRACT... Objective: To determine the frequency of the successful graft take of Integra ${ }^{\mathrm{TM}}$ and split thickness skin graft after the release of post-burn neck contracture. Study Design: Descriptive Case Series. Setting: Department of Plastic Surgery, Jinnah Burn and Reconstructive Surgery Centre, Lahore. Period: $1^{\text {st }}$ October, 2017 to $30^{\text {th }}$ September, 2018. Material \& Methods: A total of 70 cases, those who full filled the inclusion criteria were included in the study through non-probability consecutive sampling. Informed consent was obtained from all the patient. Integra was applied in all the patients after the release of contracture and excision of scar tissue and was inspected every 3-5 days. After 3 weeks, the outer layer of silicone sheet was removed and replaced by thin split-thickness skin graft. The graft was secured with skin staples, absorbent gauze and the crepe bandage. All the patients were followed up regularly and the final outcome was assessed at 6 weeks. Results: The mean age of the patients was observed as $34.51 \pm 14.19$ years with age range of 11 to 59 years. Among these 70 patients $61.4 \%$ were male and $38.6 \%$ were females. The mean body mass index was observed to be $22.59 \pm 3.68 \mathrm{~kg} / \mathrm{m}^{2}$. Out of these 70 patients, the outcome in terms of successful graft take with Integra treatment was achieved in $60(85.7 \%)$ patients. On stratification, statistically insignificant difference was observed for the effect modifiers like age, gender and BMI. Conclusion: In our study we found that Integra and STSG can be considered as one of emerging and promising modality in burn management and reconstructive surgery with the significantly high success rate in terms of complete re vascularization and skin graft take.

Key word: $\quad$ Burn, Graft Take, Integra, Neck Contracture, Split Thickness Skin Graft.

Article Citation: Mujahid AM, Tarar FA, Khalid FA, Sajjad Y, Ishaque U, Tarar MN. Outcome of successful graft take of Integra and split thickness skin graft after the release of post-burn neck contracture. Professional Med J 2021; 28(1):106112. https://doi.org/10.29309/TPMJ/2021.28.01.4668

\section{INTRODUCTION}

Morbidity of patient's related to burns i.e. contractures and hypertrophic scars has increased because of increased survival rates of more severely burn patients. Post-burn neck contracture is one of the most common burn sequelae that not only affect the movements and function of the neck and the lower face but can result in possible tracheal deviation and distortion of the cervical spine. Secondary effects of anterior cervical contractures include drooling of saliva, difficulty in breathing, lower lip and eyelids ectropion and mandibular growth inhibition in children. As these contractures cause major functional and cosmetic problems with resultant psychosocial and economic effects, operative intervention is generally recommended. ${ }^{1}$ Hence, the reconstruction of this area is a challenge to plastic surgeons in reconstructive surgery.

Despite advances in the overall care of burn injuries, post-burn contractures continue to be a formidable challenge for reconstructive surgeons in developing countries. ${ }^{2}$ The resultant post-burn contractures are often long standing, severe in nature and with secondary complications. Overall pre- and post-surgery care of these problems account for up to 50 percent of a general plastic surgeon's workload. ${ }^{3}$ In last few decades there has been significant advancement in both medical and surgical care of burn patients that resulted in considerable improvement in the overall outcome. Early excision and skin grafting is the most important modality to reduce morbidity 
and mortality rates in major and complex burns. ${ }^{4}$ Adequate soft tissue coverage is essential after the excision to prevent the physiological as well as metabolic consequences of open wounds along with prevention of bacterial invasion. ${ }^{5}$

The goal in management is to restore the form and function of the origin as much as possible. The aim of the reconstructive burn surgeon is to remove all the scar tissue in the affected area and resurface the area with supple tissue, which allows the proper movement of the neck and is esthetically pleasing. There are numerous reconstructive methods to resurface the neck after release of contracture. Split skin grafting still remains the most common modality of treatment. The other options for resurfacing the wound after release of the neck contracture besides split skin grafting include full thickness grafts, local flaps, distant flaps, tissue expansion and free tissue transfer. The frequency and severity of contracture and poor aesthetic results following the management of anterior cervical contractures by split skin grafting as well as the increasing availability of facilities for microsurgery have seen a shift in the routine treatment of neck contractures from simple contracture release and skin grafting to radical scar excision and free flap cover.

Over the past 30 years, a lot of research has been directed towards the use of artificial skin and great progress has been made in this regard. Integra is the most important breakthrough in this field, a permanent dermal substitute used in both acute and reconstructive burn surgery. ${ }^{6}$ Integra is an artificial bilayer skin substitute, covered by outer layer of silicone sheet. ${ }^{7}$ The dermal layer is organized as a matrix made up of cross-linked bovine collagen fibers and glycosaminoglycan from the shark cartilage. ${ }^{8}$ This layer provides the scaffold for neodermis formation. The host cells fibroblasts proliferate, migrate and produce a native collagen within the dermal template. The endothelial cells follow the fibroblasts migration to form a vascular network. Angiogenesis and vascularization becomes evident at approximately two to four weeks, after that outer layer of silicone can be removed and replaced by thin splitthickness graft.
In a study, for treatment of hypertrophic scars and anterior neck contracture, the role of Integra was assessed, which showed the superior cosmetic result in almost all cases. ${ }^{9}$ In another study by Lohana et al, success rate of Integra was seen in $87 \%$ patients in terms of graft take in postburn neck contracture release..$^{10}$ The rationale of my study was that if successful graft take will be achieved in significant number of patients after post burn contracture release then this study will set a base line data at national level as one of suitable option to treat the extensive post burn neck contracture with good functional and aesthetic outcome

\section{MATERIAL \& METHODS}

A descriptive case series was conducted at Jinnah Burn and Reconstructive Surgery Centre, Lahore from $1^{\text {st }}$ October, 2017 to $30^{\text {th }}$ September, 2018. The sample size of 70 cases was calculated by taking as $95 \%$ confidence level, margin of error as $8 \%$ and success of Integra $87.0 \%$. Sampling was done through Non-probability, consecutive sampling. The patients who full filled the inclusion criteria (with post-burn neck contracture, 10-60 years of age and both genders) were enrolled in the study. Patients with previous surgery for neck contracture, contractures other than burn injury, diabetes mellitus and bleeding disorders were excluded from study. After the approval from the ethical committee of Hospital, informed consent was taken from all the patients. Preoperative photography was done to compare the postoperative results and base line investigations were performed for fitness for general anesthesia. In all the patients, after release of contracture and excision of scar tissue, Integra was applied and covered with Vaseline soaked gauze, together with dry absorbent gauze and the crepe bandage. Inspection of Integra was done at every 3-5 days. After 3 weeks, the outer layer of silicone sheet was removed and replaced with thin split-thickness skin graft as per manufacturer advice. All patients were followed-up regularly and outcome was assessed by consultant plastic surgeon having ten-year post fellowship experience. All the collected data were entered and analyzed by using SPSS version 20.0. Age and duration of contracture was presented as mean and standard 
deviation. Frequency and percentages were calculated for gender, successful / unsuccessful graft take. Stratification was done for age, gender, $\mathrm{BMI}$ and duration of contracture by using Chisquare test. A P-value of $\leq 0.05$ was considered as significant.

\section{RESULTS}

A total of 70 patients with post-burn neck contracture who underwent for Integra and split thickness skin graft were included in the study after taking an informed consent. The mean age of the patients was $34.51 \pm 14.19$ years of which the minimum age was 11 year and the maximum of 59 years. Out of 70 patients, there were $43(61.4 \%)$ males and 27 (38.6\%) females. The mean body mass index was calculated to be $22.59 \pm 3.68 \mathrm{~kg} / \mathrm{m}^{2}$ (range $17-32 \mathrm{~kg} / \mathrm{m}^{2}$ ). The mean duration of contracture among these patients was noticed to be $595.42 \pm 177.31$ days with the range of 225 days to 1003 days. Among these, $60(85.7 \%)$ cases had successful outcome in terms of complete vascularization and graft take after 6-weeks of follow-up (Figure-1,2,3) and unsuccessful outcome was detected in 10 $(14.3 \%)$ of the patients. (Table-I)

On stratification it was observed that out of 70 patients who achieved the successful outcome in terms of complete vascularization and graft take, the maximum number of patients belongs to (10-25) years age group i.e. 21(91.3\%) out of 23 followed by (26-45) years age group i.e. 24(82.8 $\%)$ out of 29 and similar range was found in the age group (46-60) years 15 (83.3\%) patients from 18 cases. There was statistically insignificant difference observed with respect to age and successful outcome (P-value $=0.645)$. When data was stratified for gender it was revealed that $39(90.7 \%)$ out of 43 male cases were achieved successful outcome and 21 (77.8\%) out of 27 females attained successful Integra graft. However; statistically insignificant difference was found between gender and success of the Integra and split thickness skin graft (P-value $=0.133$ ). Statistically insignificant difference was observed for confounding variable like BMI as maximum number of patients were associated with nonobese group i.e. 47 (82.5\%) out of 57 and all 13
(100.0\%) obese patients achieved the successful outcome in terms of complete vascularization of Integra (P-value $=0.103)$ (Table-II).

\begin{tabular}{|l|c|c|}
\hline Variables $\mathbf{n = 7 0}$ & \multicolumn{1}{|c|}{ Frequency } & Percentage \\
\hline Age (In Years) & Mean & $\mathbf{3 4 . 1 5 + 1 4 . 1 9}$ \\
\hline$<25$ & 23 & 32.0 \\
\hline $30-60$ & 47 & 58.0 \\
\hline Gender & & \\
\hline Male & 43 & 61.4 \\
\hline Female & 27 & 38.6 \\
\hline BMI Mean 22.59+3.68 & \\
\hline$<27$ & 57 & 81.4 \\
\hline$>27$ & 13 & 18.6 \\
\hline Duration of Contracture Mean 595.42 & $\mathbf{1 7 7 . 3 0}$ \\
\hline$<500$ days & \\
\hline > 500 days & \\
\hline Integra Outcome & \\
\hline Successful & 60 & \\
\hline Unsuccessful & 10 & \\
\hline \\
Table-I. Demographic and clinical profile of patients \\
\hline
\end{tabular}

\section{DISCUSSION}

Post burn contractures and hypertrophic scars frequently occur in deep dermal or full thickness burn injuries that commonly involve the mobile body parts like neck and axilla. Improper or inadequate initial treatment and lack of physiotherapy are one of major causes. The head and neck areas being exposed are significantly vulnerable to burn injury and subsequent scar deformities that cannot be camouflaged with routine clothing. ${ }^{11}$

Mortality and morbidity from more complex and major burns has been reduced owing to advancement in both medical and surgical care. Greater understanding of physiological and metabolic consequences of burn injuries as well as the better patient and wound care have played a role in this regard. ${ }^{12}$ Early excision and closure of burn wound defect are considered as the standard of care to achieve favorable outcomes. But this can be challenging when the body surface area of over $40 \%$ is involved resulting in limited availability of donor sites. 


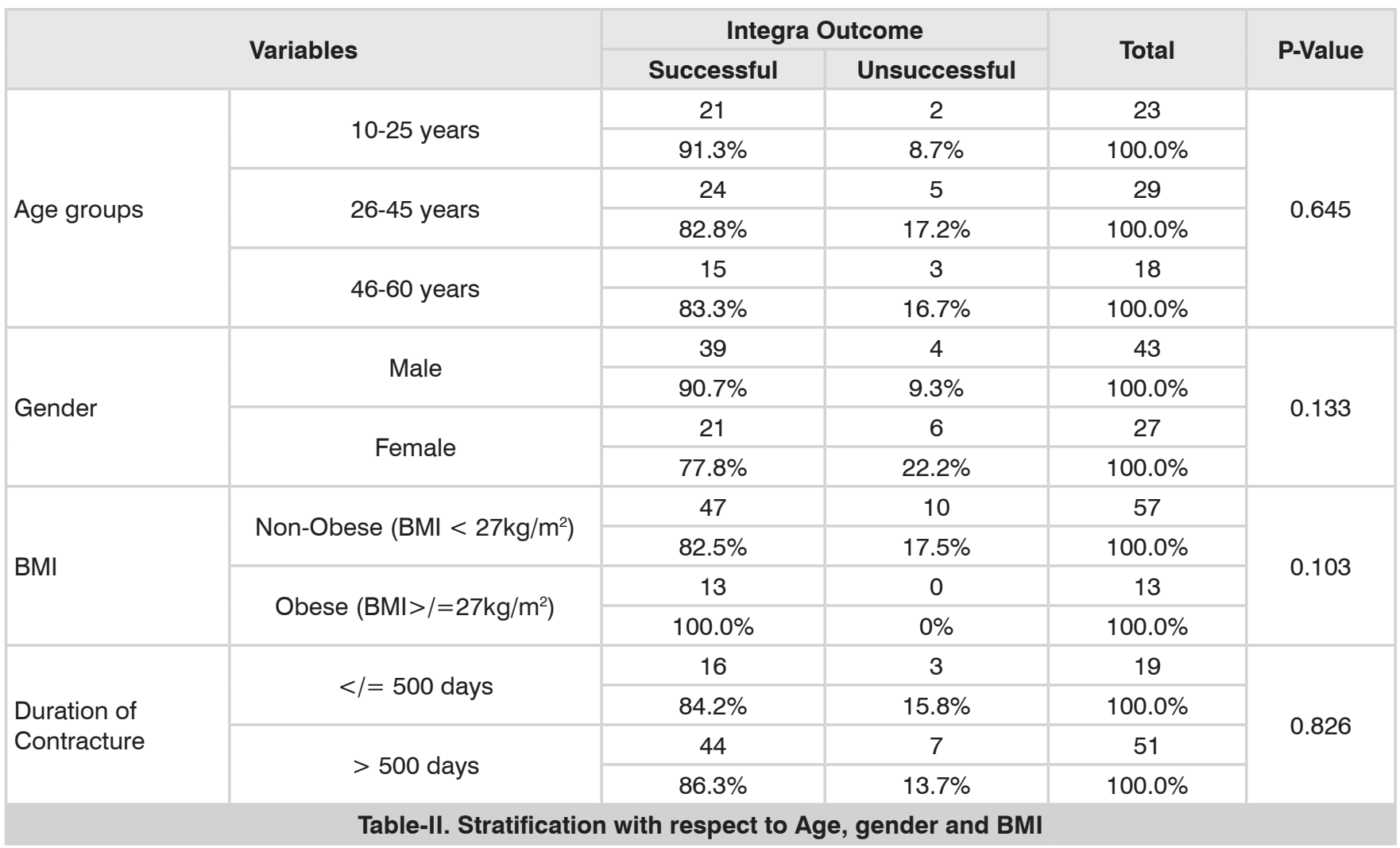

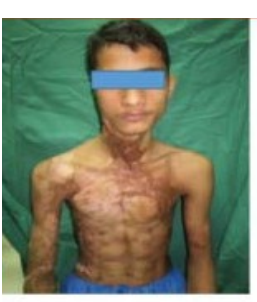

A

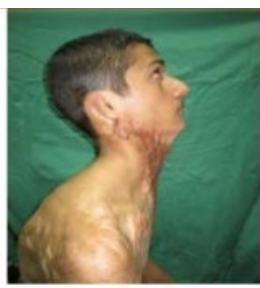

B

FIG.1 pre op pictures A \& B, intra op pictures $C, D \& E$, post op pictures $F \& G$

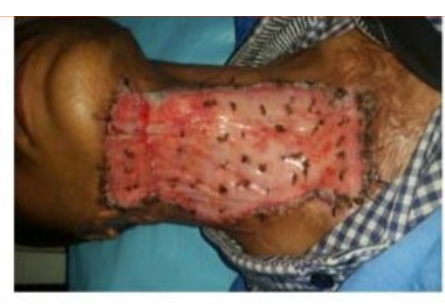

c

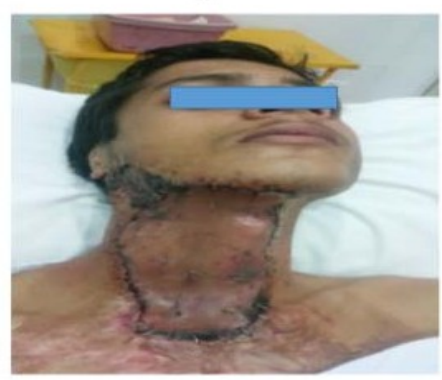

F

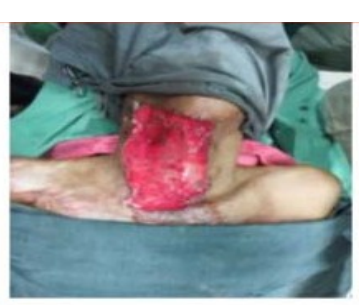

D

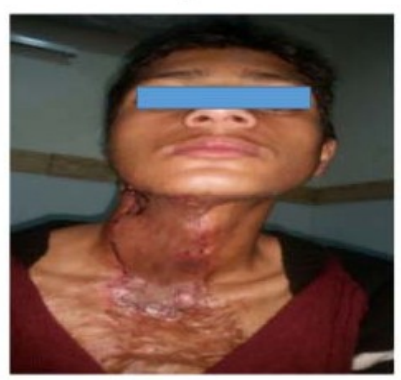

G

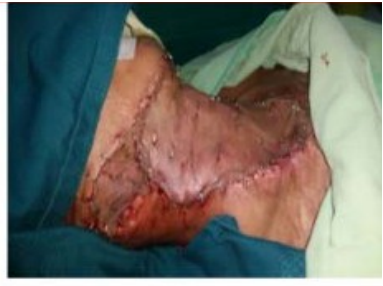

E

Figure-1

In the last few decades, significant and rapid expansion has been observed in the number of bioengineered skin substitutes to achieve better functional and aesthetic outcomes. In 1981, Burke used the Integra in 10 patients to provide temporary wound cover of up to sixty percent of the total body surface area. ${ }^{13}$ Since that,
Integra has been established as an important treatment option in the management of acute and reconstructive burn surgery. ${ }^{14}$ Lee et al., reported seven cases of complex burn injuries involving the lower limb that was resurfaced with Integra and split thickness skin graft. 


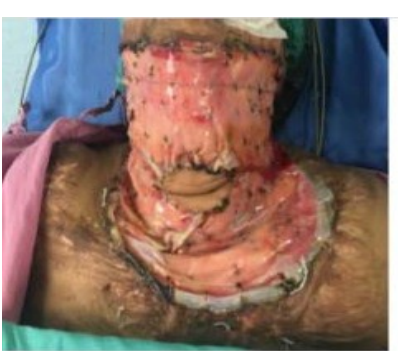

A

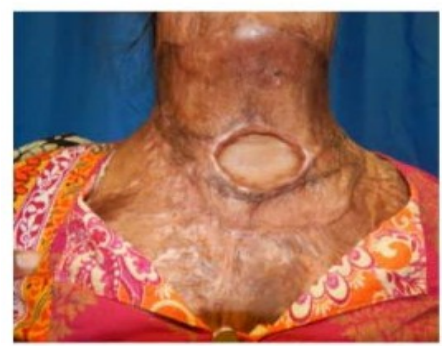

$\mathrm{E}$

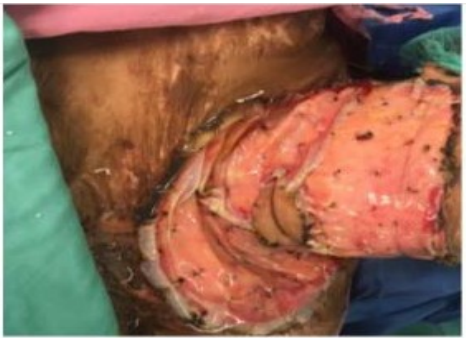

B

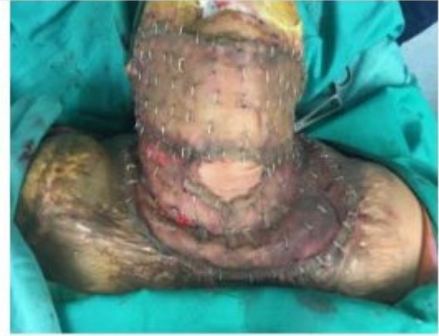

C

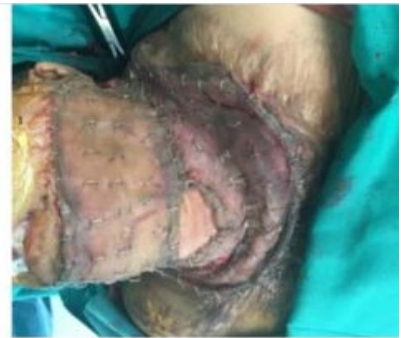

D

FIG. 2 Intra op pictures with integra in place $(A, B)$, Replacement of silicon layer with STSG pictures (C,D), Post op pictures with complete take of graft (E,F)

Figure-2

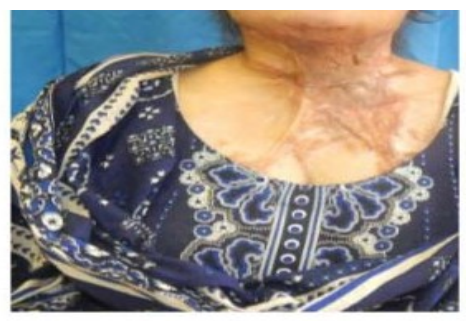

A

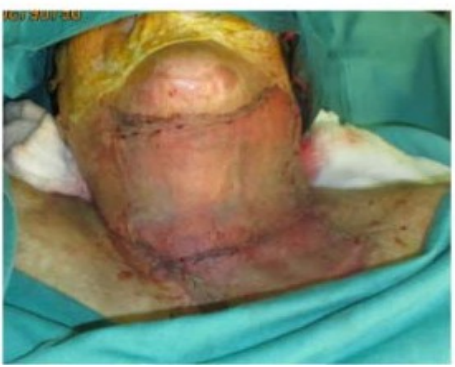

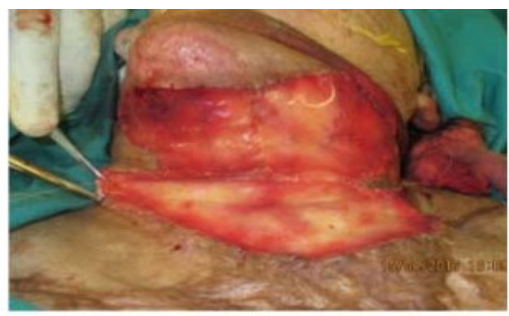

B

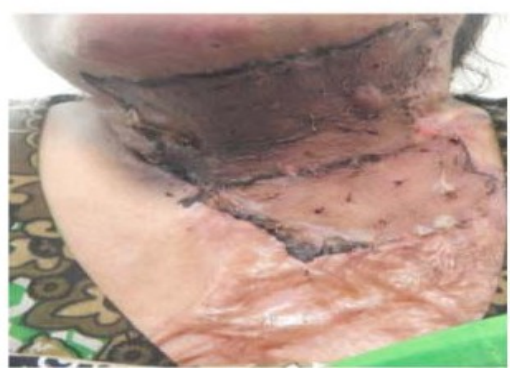

Figure-3
FIG. 3 Pre op picture (A), Intra op pictures with integra \& STSG $(B, C)$, Post op picture with complete take of graft (D)
All patients had stable wound coverage and did not required further surgical procedure for wound closure. Komorowska et al also reported their experience on seven patients with complex scalp wounds, graft take was successful in all cases except one case of recurrence requiring further treatment.

On microscopy and histological analysis of Integra It showed the complete replacement of the artificial skin with the host dermis. Both dermal layers showed remarkable differentiation and are structurally comparable to normal skin. The new collagen is histologically indistinguishable from normal dermal collagen and complete revascularization was achieved within two to four weeks.

Our study results showed that the average age of 70 patients was observed to be 34.51 years with the range of $11-59$ years, out of which $61.4 \%$ were male and $38.6 \%$ were female whereas the 
study done by Lohana et al reported that out of 23 patients, and 9 (39\%) male and 14 (61\%) were female, with mean age of 28 years, ranging from 4-73 years. ${ }^{10}$ Similarly, study results reported by Seo nearly matched with our results with respect to age i.e. the mean age of $32.4 \pm 16.1$ years (range 4-69 years) of 28 patients there were fifteen males and 13 females. ${ }^{11}$ Another study by J. A Hunt, reported the results for 6 patients who underwent Integra and skin grafting after the release of post burn neck contracture. The mean age of patients was 40 years of which $66 \%$ were females and $33 \%$ were male. ${ }^{15}$ Radial forearm free flap donor site were covered by Integra and split skin graft in single stage, but for much smaller defect than that created after the release of significant neck contracture. They reported that both the Integra and skin graft can be meshed 1.5:1 to improve the likelihood of graft survival. But the resultant mesh pattern may be considered to be suboptimal by many authors. ${ }^{16}$

We found a significantly high percentage of successful outcome of Integra and split thickness skin graft in terms of complete vascularization and graft take i.e. $85.7 \%$ and Integra was unsuccessful in $14.3 \%$ of the cases. Similarly results by Lohanan et al reported the use of Integra in acute burns in $15(66 \%)$ and secondary burn reconstruction in $8(34 \%)$ cases. The mean time from Integra to grafting was 23 days and mean graft take was $87 \%$.In the same way Hunt JA reported that mean hospital stay was 24 days (range, 19-30 days), with the mean take of the Integra was $90 \%$ (range $70-100 \%$ ) and for the skin graft was $85 \% .^{16}$

In our study, we stratified the results with respect to effect modifiers like age, gender, BMl and duration of contracture, but all variables had no effect on the outcome of Integra i.e. success and insignificant results were perceived on comparison.

\section{CONCLUSION}

Our study results proved that Integra is a safe and reliable alternative option. It can be considered as one of promising modality in acute burn management and reconstructive surgery with the significantly high success rate in terms of complete re vascularization and skin graft take

\section{CONFLICT OF INTEREST}

Authors have no financial or personal interests with any people or organisation that would influence this work

Copyright@ 20 May, 2020.

\section{REFERENCES}

1. Mody NB, Bankar SS, Patil A. Post-Burn contracture Neck: Clinical profile and management. J Clin Diaqn Res 2014; 8(10).

2. Saaiq M, Zaib S, Ahmad S. The menace of post-burn contractures: A developing country's perspective. Ann Burns Fire Disasters. 2012; 25(3):152-58.

3. Goel A, Shrivastava P. Post-burn scars and scar contractures. Indian J Plast Surg. 2010; 43:63-71.

4. Makboul M, El-Oteify M. Classification of post-burn contracture neck. Indian J Burns. 2013; 21:50-4.

5. Mathur R, Jain PK, Chakotiya PS, Rathore P. Anaesthetic and airway management of a post-burn contracture neck patient with microstomia and distorted nasal anatomy. Indian J Anaesth. 2014; 58:210-3.

6. Cuadra A, Correa G, Roa R, Pineros JL, Norambuena $\mathrm{H}$, Searle $\mathrm{S}$, et al. Functional results of burned hands treated with Integra(R). J PlastReconstrAesthet Surg. 2012; 65(2):228-34.

7. VanZuijlen PPM, Gardien KLM, Jaspers MEH, Bos EEJ, Baas DC, van Trier AJM, et al. Tissue engineering in burn scar reconstruction. Burns Trauma. 2015; 3:18.

8. Weigert R, Choughri H, Casoli V. Management of severe hand wounds with Integra( $R$ ) dermal regeneration template. J Hand Surg Eur. 2011; 36(3):185-93.

9. Author. Initial treatment of Integra in the treatment of Post-burn anterior cervical neck contracture. Brit $\mathrm{J}$ Plast Surg 2000; 53(8): 652-658.

10. Lohana $P$, Hassan $S$, Watson $S B$. Integra ${ }^{T M}$ in burns reconstruction: Our experience and report of an unusual immunological reaction. Ann Burns Fire Disasters. 2014; 27(1):17-21.

11. Seo DK, Kym D, Hur J. Management of neck contractures by single dermal substitutes and skin grafting in extensive burn patients. Ann Surg Treat Res 2014; 87(5): 253-259. 
12. Fitton AR, Drew P, Dickson WA. The use of a bilaminate artificial skin substitute (Integra) in acute resurfacing of burns: an early experience. $\mathrm{Br} \mathrm{J}$ Plast Surg 2001; 54(3):208-12.

13. Burke JF, Yannas IV, Quinby WC, Bondoe CC, Jung WK. Successful use of a physiologically acceptable artificial skin in the treatment of extensive burn injury. Ann Surg 1981; 194: 413-28.

14. Chalmers RL, Smock E, Geh JL. Experience of Integra in cancer reconstructive surgery. J Plast Reconstr Aesthet Surg 2010; 63: 2081-90.
15. Hunt JA, Moisidis I, Haertsch P. Initial experience of Integra in the treatment of post-burn anterior cervical neck contracture. Br J Plast Surg 2000; 53(Issue 8): 652-685.

16. Belek KA, Alkureishi LWT, Dunn AA, et al. Singlestage reconstruction of a devastating antebrachial injury with the brachial artery, median nerve and soft tissue deficit: A case report and review of the literature. EPlasty 2010; 10: e33.

\section{AUTHORSHIP AND CONTRIBUTION DECLARATION}

\begin{tabular}{|c|l|l|}
\hline Sr. \# & \multicolumn{1}{|c|}{ Author(s) Full Name } & \multicolumn{1}{|c|}{ Contribution to the paper } \\
\hline 1 & Abdul Malik Mujahid & $\begin{array}{l}\text { Principal contributor, Conceptu- } \\
\text { alization and design of research } \\
\text { work, data collection. } \\
\text { Data collection, statistical } \\
\text { analysis, interpretation of data. } \\
\text { Writing of manuscript, resutls } \\
\text { analysis. } \\
\text { Drafting, literature search, data } \\
\text { collection, final review. } \\
\text { Literature search, statistical } \\
\text { analysis, revision of manuscript. } \\
\text { Drafting, review of resutls and } \\
\text { final approval. }\end{array}$ \\
\hline 6 & Farrukh Aslam Khalid & Yawar Sajjad \\
\hline
\end{tabular}

